\title{
In-situ Formation of Ag Nanoparticles in Spherical \\ Polyacrylic Acid Brushes by UV Irradiation
}

\author{
Yan Lu*, Yu Mei, Marc Schrinner, Matthias Ballauff \\ Physikalische Chemie I, University of Bayreuth, 95440 Bayreuth, Germany \\ Michael W. Möller, Josef Breu
}

Anorganische Chemie I, Universität Bayreuth, 95440 Bayreuth, Germany

Supplementary Material 


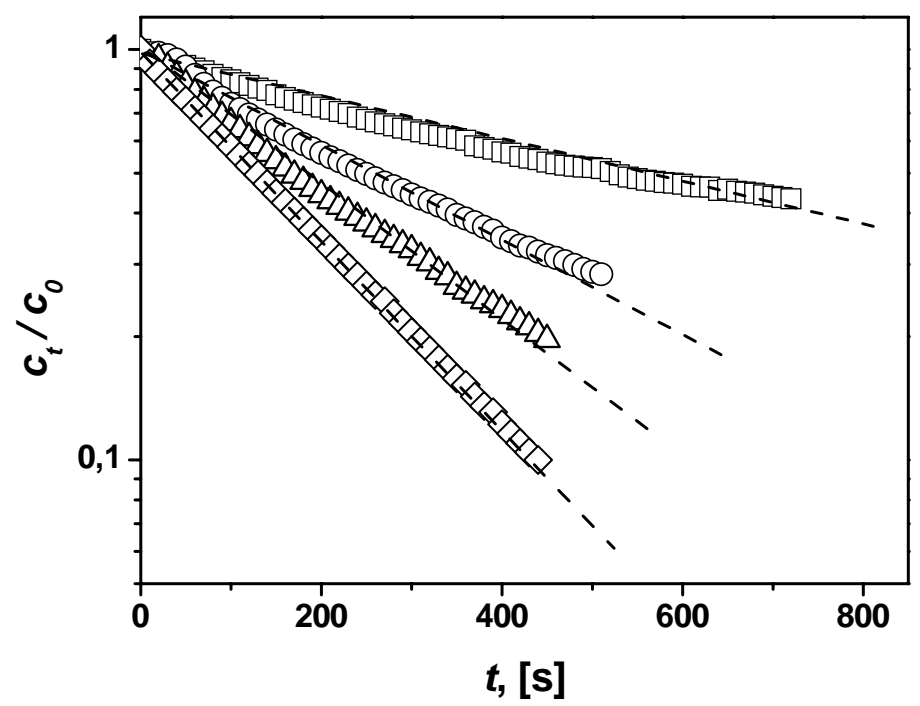

Figure 1. Influence of Ag-composite particles (PS-PAA-Ag) concentration on the reduction of 4-nitrophenol. The concentration of the reactants was as follows: [4-nitrophenol] = $0.1 \mathrm{mmol} / \mathrm{l},\left[\mathrm{NaBH}_{4}\right]=10 \mathrm{mmol} / \mathrm{l}, \mathrm{T}=20^{\circ} \mathrm{C}$. Parameter of the different curves is the concentration of composite particles in the solution. Quadrangles: $4.05 \mathrm{mg} / \mathrm{l}$; circles: 6.08 mg/l; triangles: $8.10 \mathrm{mg} / \mathrm{l}$; diamonds: $10.13 \mathrm{mg} / \mathrm{l}$. 